\title{
La silve. Histoire d'une écriture libérée en Europe, de l'Antiquité au XVIII siècle, P. Galand et S. Laigneau (dir.)
}

\section{G. Matteo Roccati}

\section{(2) OpenEdition}

Journals

\section{Édition électronique}

URL : http://journals.openedition.org/studifrancesi/10495

DOI : 10.4000/studifrancesi.10495

ISSN : 2421-5856

Éditeur

Rosenberg \& Sellier

\section{Édition imprimée}

Date de publication : 1 décembre 2017

Pagination : 523

ISSN : 0039-2944

\section{Référence électronique}

G. Matteo Roccati, «La silve. Histoire d'une écriture libérée en Europe, de l'Antiquité au xvIII siècle, P. Galand et S. Laigneau (dir.) », Studi Francesi [En ligne], 183 (LXI | III) | 2017, mis en ligne le 01 février 2018, consulté le 22 janvier 2021. URL : http://journals.openedition.org/studifrancesi/10495; DOI : https://doi.org/10.4000/studifrancesi.10495

Ce document a été généré automatiquement le 22 janvier 2021.

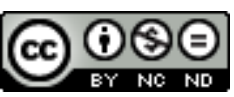

Studi Francesi è distribuita con Licenza Creative Commons Attribuzione - Non commerciale - Non opere derivate 4.0 Internazionale. 


\title{
La silve. Histoire d'une écriture libérée en Europe, de l'Antiquité au XVIII siècle, P. Galand et S. Laigneau (dir.)
}

\author{
G. Matteo Roccati
}

\section{RÉFÉRENCE}

La silve. Histoire d'une écriture libérée en Europe, de l'Antiquité au XVIII siècle, Études réunies par Perrine GALAND et Sylvie LAIGNEAU, Turnhout, Brepols, 2013, «Latinitates» V, 732 pp.

1 Le volume est le fruit remanié d'un colloque qui s'est tenu à Gand en 2008, il rassemble une trentaine de contributions, regroupées en sept parties: I, «Silva, le terme et le "genre": définitions antiques et humanistes», II, «La silve et les arts, dans l'Antiquité et à la Renaissance», III, «La silve dans la littérature antique tardive», IV, «Présence de la silve au Moyen Âge», V, «La silve dans la littérature de la Renaissance I. L'érudition humaniste», VI, «La silve dans la littérature de la Renaissance II. La question des genres», VII, «Le devenir de la silve aux XVII et XVIII ${ }^{\mathrm{e}}$ siècles».

2 L'Avant-propos de Perrine Galand (Peut-on se repérer dans la silve?, pp. 5-13) présente clairement les caractéristiques de cette écriture particulière: poésie de circonstance qui se veut autobiographique et spontanée, nourrie d'érudition et refusant toute appartenance à un genre chez Stace, elle devient au fil des périodes imitation docte ou forme d'écriture «dissidente», utilisée au XVIII ${ }^{e}$ siècle comme mode anti-conventionnel d'exposition du savoir. Les articles concernent pour la plupart des textes latins de l'Antiquité, classique et tardive, et de la Renaissance (les Silvae de Stace sont redécouvertes par Poggio Bracciolini en 1417), la partie consacrée au Moyen Âge en réunit trois: Francine MORA LEBRUN, Sidoine Apollinaire et Benoit de Sainte-Maure: de la silve au dit?, pp. 253-266, à propos de quelques digressions dans le Roman de Troie; Alice LAMY, «Silva silvestris». Matière d'une écriture silvaine dans la «Cosmographia» de Bernard Silvestre, 
pp. 267-287; Florent RoUILLÉ, Le goût pour l'obscurité dans l'épopée latine du XII siècle, un avatar médiéval de l'écriture de la silve?, pp. 289-313. 